\title{
CARACTERIZAÇÃO MORFOLÓGICA DE FRUTOS, SEMENTES, PLÂNTULAS E MUDAS DE PAU-BRASIL (Caesalpinia echinata LAMARCK) ${ }^{1}$
}

\begin{abstract}
Robério Anastacio Ferreira ${ }^{2}$ e Soraia Stefane Barbosa Barretto ${ }^{3}$
RESUMO - Estudos relacionados à morfologia vegetal com espécies florestais nativas têm sido ampliados nos últimos anos, em face da sua importância sob os aspectos taxonômicos ou por serem de grande utilidade na identificação de frutos, sementes, plântulas e mudas, em laboratórios de análises de sementes, em viveiros de produção de mudas ou em estudos que avaliem a regeneração natural em ecossistemas florestais. Porém, diante da grande diversidade de espécies, ainda não é possível encontrar informações suficientes para subsidiar tais estudos e nem coleções em herbários para um grande número de espécies nativas. Assim, este trabalho foi realizado com o objetivo de caracterizar morfologicamente frutos, sementes, plântulas e mudas de pau-brasil (Caesalpinia echinata Lam.) - Fabaceae, Subfamília Caesalpinioideae. Foram realizadas, inicialmente, avaliações das características morfométricas e morfológicas externas e internas dos frutos e sementes. Em seguida, foram realizadas descrições do desenvolvimento inicial de plântulas e mudas. Considerando-se as análises descritivas da espécie, as informações de frutos, sementes, plântulas e mudas podem ser empregadas com segurança em trabalhos de identificação das espécies, tanto em trabalhos de laboratórios e viveiros quanto em estudos de campo sobre a ecologia dessa espécie. Especial atenção pode ser dada ao fruto legume seco, ao embrião, à germinação epígea fanerocotiledonar e à presença de acúleos nas fases jovens (plântulas e mudas), que são importantes para a identificação da espécie. Os caracteres que são comuns a outras espécies de Fabaceae, da Subfamília Caesalpinioideae, corroboram o caráter taxonômico dos aspectos morfológicos.
\end{abstract}

Palavras-chave: Taxonomia; Espécies florestais; Ecologia.

\section{MORPHOLOGICAL CHARACTERIZATION OF FRUITS, SEEDS, PLANTULES AND SEEDLINGS OF BRAZIL WOOD (Caesalpinia echinata LAMARCK)}

\begin{abstract}
Studies related to plant morphology with native forest species have been expanded in recent years, given their importance in the taxonomic aspects or for being useful in identifying fruits, seeds, plantules and seedlings in seed testing laboratories, in nurseries to produce seedlings, or in studies that assess the natural regeneration in forest ecosystems. However, given the great diversity of species, it is still not possible to find enough information to support such studies nor collections in herbarium for a large number of native species. This work was carried out to characterize the morphology of fruits, seeds, plantules and seedlings of Brazil wood (Caesalpinia echinata Lam) - Fabaceae, Subfamily Caesalpinioideae). Initially assessments of morphometric and internal and external morphological characteristics of fruits and seeds were performed. Then, there were descriptions of early development of plantules and seedlings. Considering the descriptive analyzes of the studied species, information about fruits, seeds, plantules and seedlings can be safely employed in efforts to identify the species, both in laboratories and nurseries or in field studies on the ecology of this species. Special attention can be given to dry fruit, and the embryo, the epigeal phanerocotylar germination and the presence of aculei in the young stages (plantules and seedlings) are important for species identification. The characters that are common to other species of Fabaceae, Subfamily Caesalpinioideae corroborate the taxonomic importance of morphological characters.
\end{abstract}

Keywords: Taxonomy; Forest species; Ecology.

\footnotetext{
${ }^{1}$ Recebido em 25.03.2013 aceito para publicação em 24.03.2015.

${ }^{2}$ Universidade Federal de Sergipe, Centro de Ciências Agrárias e Aplicadas, Departamento de Ciências Florestais, São Cristóvão, Sergipe, Brasil. E-mail: <roberioaf@yahoo.com.br>.

${ }^{3}$ Universidade Federal de Sergipe, Mestrado em Ecologia e Conservação, São Cristóvão, Sergipe, Brasil. E-mail:

<stefanebarretto@bol.com.br>.
} 


\section{INTRODUÇ̃̃O}

A morfologia vegetal é o ramo da Botânica que estuda as formas e estruturas das plantas (GONÇALVES; LORENZI, 2011), sendo imprescindível na compreensão do ciclo de vida e crescimento de espécies florestais (MOURÃO et al., 2002). Isso porque, além de ser útil para a identificação das espécies, pode auxiliar em estudos envolvendo a avaliação de regeneração natural dos ecossistemas, análise do ciclo biológico, formas de manejo e definição de estratégias para a conservação das espécies e, até mesmo, no desenvolvimento de técnicas eficientes na produção de mudas (BATISTA et al., 2011).

O aumento dos trabalhos relacionados à caracterização morfológica de espécies florestais nativas deriva do crescente interesse na propagação e expansão do comércio de sementes e mudas, que demandam informações básicas sobre a morfologia e características germinativas das sementes dessas espécies (SILVA; CARVALHO 2008), assim como o conhecimento do comportamento das espécies durante o seu ciclo de produção em viveiro.

As informações sobre os caracteres morfológicos de frutos e sementes podem fornecer dados importantes para identificação e conhecimento do comportamento das espécies nas diferentes regiões ecológicas e determinação da variabilidade da espécie, bem como no estudo do tipo de dispersão e dos agentes dispersores (ALMEIDA JÚNIOR et al., 2010), aspectos que podem ser considerados fundamentais do ponto de vista ecológico e para subsidiar programas de reflorestamentos e recuperação de áreas degradadas.

Quanto aos estádios de plântulas e mudas, consideradas fases críticas do estabelecimento das espécies no ambiente, vários autores destacaram a importância da morfologia de plântulas, como subsídio para estudos de sucessão e regeneração natural. Entre os trabalhos realizados com essa finalidade, podem-se citar Rego et al. (2010), que descreveram as espécies Blepharocalyx salicifolius (H.B.K.) Berg. e Myrceugenia gertii Landrum; e Oliveira et al. (2010) e Sousa et al. (2010), que descreveram, respectivamente, Cenostigma tocantinum Ducke, Hymenolobium petraeum Ducke e Tamarindus indica L.; Ramos et al. (2010), que descreveram Moringa oleifera Lam.; Battilani et al. (2011), que descreveram Guibourtia hymenifolia (Moric.) J. Leonard; Gurski et al. (2012), que descreveram Ormosia arborea (Vell.) Harms e Ormosia fastigiata Tul.; e Silva et al. (2012), que descreveram Sideroxylon obtusifolium (Roem. e Shult.) Penn.

Apesar de considerável avanço observado nos estudos sobre a morfologia vegetal, ainda se observa que há grande carência de informações, principalmente nos estádio de plântulas e mudas, em face da grande biodiversidade observada nos ecossistemas florestais. Assim, a morfologia de frutos, sementes, plântulas e mudas é necessária, uma vez que há grande número de espécies sem informações sobre seus caracteres morfológicos.

Ressalta-se que a identificação sistemática é baseada fundamentalmente (tradicionalmente) na morfologia da flor. E, ainda, outra importante contribuição nesse ramo está relacionada ao uso de características anatômicas, que também são bastante empregadas para identificação das espécies vegetais.

No Estado de Sergipe, as áreas vegetadas, em grande parte, foram ocupadas para a formação das cidades, exploração agrícola e pecuária, de forma indiscriminada e sem qualquer planejamento quanto à sustentabilidade ambiental e à estrutura das populações vegetais mais relevantes, considerando-se os seus diversos usos: lenha e carvão, forrageiro, alimentar, medicinal e madeireiro. E, ainda, sem considerar a importância das espécies para o equilíbrio ecológico dos ambientes onde ocorrem. Em consequência da excessiva exploração, verifica-se significativa redução das populações naturais das espécies arbóreas nativas. Em alguns casos, várias delas se tornam raras ou são levadas ao desaparecimento em determinadas áreas.

Considera-se que no Estado de Sergipe não se têm registros precisos da ocorrência de pau-brasil, necessitando-se, assim, estudos que possam elucidar a sua ocorrência e presença de populações naturais. De acordo com Ulibarri (1996), o gênero Caesalpinia apresenta distribuição pantropical, contendo cerca de 150 espécies; e, na América do Sul, encontram-se 40 registradas, ocorrendo distribuídas em áreas desde áreas semidesérticas até as áreas de matas.

Assim, este trabalho foi realizado com o objetivo de caracterizar a morfologia de frutos, sementes, plântulas e mudas de pau-brasil (Caesalpinia echinata Lamarck), de ocorrência natural no Estado de Sergipe, na tentativa de auxiliar trabalhos futuros sobre a taxonomia e aspectos relacionados à ecologia da espécie.

Revista Árvore, Viçosa-MG, v.39, n.3, p.505-512, 2015

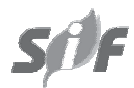




\section{MATERIAL E MÉTODOS}

Os frutos foram coletados em árvores matrizes localizadas no Campus de São Cristóvão, na Universidade Federal de Sergipe, Município de São Cristóvão, SE $\left(10^{\circ} 55^{\prime} 32^{\prime \prime S ~}\right.$ e 3706'08' W). Os indivíduos foram plantados e apresentam idade superior a 20 anos. A coleta foi realizada diretamente de cinco árvores matrizes distantes no mínimo $50 \mathrm{~m}$ entre si, com o auxílio de podão e lona plástica, impedindo que os frutos caíssem diretamente no chão. Os frutos e sementes que apresentavam sinais de deterioração ou sementes malformadas e com injúrias foram eliminados.

Após a coleta, esses frutos foram mantidos à sombra durante o período de $24 \mathrm{~h}$ para completar a secagem, no Viveiro Florestal do Departamento de Ciências Florestais, da Universidade Federal de Sergipe, quando ocorreu a sua abertura espontânea. Após beneficiadas, as sementes foram transportadas para o Laboratório de Sementes para realizar-se a caracterização imediata.

A caracterização morfológica de frutos e sementes foi realizada no Laboratório de Sementes do Departamento de Ciências Florestais da Universidade Federal de Sergipe. Foram realizadas, inicialmente, avaliações morfométricas, a partir de uma amostra aleatória de 100 frutos e 100 sementes, bem como determinadas as medidas de comprimento, largura e espessura. Para tal, foi utilizado um paquímetro digital (Digimess e régua milimetrada), obtendo-se, assim, as medidas mínimas, médias e máximas.

Na caracterização morfológica dos frutos, foram considerados os seguintes aspectos: tipo, coloração, dimensões, textura e consistência do pericarpo, deiscência e número de sementes por fruto. Nas sementes, os aspectos externos observados e descritos foram aqueles mais frequentemente empregados em estudos de caracterização morfológica: coloração, textura e consistência do(s) tegumento(s), forma e bordo das sementes, posição do hilo, da micrópila e da rafe. Os aspectos internos observados foram: cotilédones, eixo hipocótilo-radícula e plúmula.

Para facilitar o estudo da morfologia interna, as sementes foram hidratadas e as observações, feitas com o auxílio de microscópio estereoscópico binocular (4x). Os métodos e os termos empregados foram baseados nos trabalhos de Rego et al. (2010) e Barretto e Ferreira (2011).

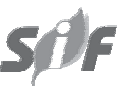

Para a caracterização morfológica de plântulas e mudas, foram produzidos 100 indivíduos da espécie, os quais foram regados sempre que necessário.

Para a fase de plântulas, realizada no laboratório, as sementes foram semeadas em caixas gerbox $(11 \mathrm{x}$ $11 \times 2,5 \mathrm{~cm}$ ), utilizando-se como substrato areia (lavada, peneirada e esterilizada em estufa com circulação de ar a $120^{\circ} \mathrm{C}$, por $24 \mathrm{~h}$ ). As sementes foram semeadas sobre substrato e mantidas em germinador tipo BOD, com temperatura constante de $25^{\circ} \mathrm{C}$, sob luz contínua. Para mantê-las hidratadas, foi feita a reposição de água sempre que necessário. A sala de germinação foi climatizada, mantendo-se a temperatura ambiente em $28^{\circ} \mathrm{C} \pm 2{ }^{\circ} \mathrm{C}$. Para evitar a infestação por microrganismos, as sementes foram desinfetadas com água sanitária $2 \%$ durante $2 \mathrm{~min}$, seguida de lavagem em água destilada. As avaliações foram realizadas a cada dois dias para descrição das características diferenciativas, desde o intumescimento até a formação das estruturas essenciais normais (raiz primária, hipocótilo, cotilédones, epicótilo e protófilos abertos).

O estádio de plântula foi considerado quando os protófilos já estavam totalmente formados e o de muda, a partir do surgimento do $2^{\circ}$ protófilo. Os elementos vegetativos descritos e ilustrados foram os mesmos sugeridos por Roderjan (1983): raiz (principal e secundária), colo, hipocótilo, cotilédones, epicótilo, protófilos de $1^{\underline{a}}$ ordem, caule jovem e protófilos de $2^{\underline{a}}$ ordem.

Para caracterização da fase de mudas, realizada no Viveiro Florestal, foi utilizado como recipiente o saco de polietileno preto $(14 \times 25 \mathrm{~cm})$, tendo como substrato terra de subsolo, areia e esterco de curral curtido, na proporção $3: 1: 1$. Uma adubação inicial foi realizada com $5 \mathrm{~kg}$ de superfosfato simples $+500 \mathrm{~g}$ de cloreto de potássio $+300 \mathrm{~g}$ de FTE-BR12 para cada $\mathrm{m}^{3}$ de substrato, e a de cobertura foi iniciada a partir de 30 dias após a emergência, utilizando-se $60 \mathrm{~g}$ de cloreto de potássio $+25 \mathrm{~g}$ de sulfato de amônio diluído em $10 \mathrm{~L}$ de água.

Os termos empregados para essas fases estão de acordo com os trabalhos de Barroso et al. (1999), Ferreira et al. (2001), Abud et al. (2010) e Barretto e Ferreira (2011). Todos os aspectos morfológicos de frutos e sementes e todas as fases de desenvolvimento de plântulas e mudas foram fotografados com o auxílio de máquina digital, na tentativa de auxiliar na

Revista Árvore, Viçosa-MG, v.39, n.3, p.505-512, 2015 
identificação da espécie, facilitar o seu reconhecimento em laboratórios e em viveiros de produção de mudas e, ainda, auxiliar estudos sobre a sua ecologia, considerando-se os aspectos da regeneração natural.

\section{RESULTADOS}

3.1. Caracterização morfológica do fruto (Figura 1) - O fruto é um legume seco, deiscente, simples, monospérmico a polispérmico, com número de sementes variando de 1 a 5 . O comprimento médio é de $6,16 \mathrm{~cm}$ (variando de 4,01 a 6,70 cm), a largura média é de $2,35 \mathrm{~cm}$ (variando de 1,50 a 2,44 cm) e a espessura média é de $2,11 \mathrm{~cm}$ (variando de 0,11 a 0,30 cm); é estipitado, apresentando pedúnculo de coloração marrom, consistência lenhosa e com estrias horizontais. O epicarpo apresenta grande número de acúleos na sua superfície, com coloração verde quando jovem e marrom quando maduro; de formato oblongo e delgado, com apículo estipuliforme; a base é acunheada e o bordo, inteiro. O mesocarpo é seco, de coloração verde-clara, com escamações, e o endocarpo apresenta-se seco.

3.2. Caracterização morfológica da semente (Figuras 2e3) - As sementes são estenospérmicas, altamente polidas, assimétricas nos lados, córneas, rugosas, bicolores, de coloração marrom-avermelhada; o comprimento médio é de 14,02 mm (variando de 10,5 a 17,14 mm), a largura média é de 12,02 mm (variando de 8,2 a 14,4 mm); a espessura média é de 2,68 mm (variando de 0,95 a 3,79 mm);

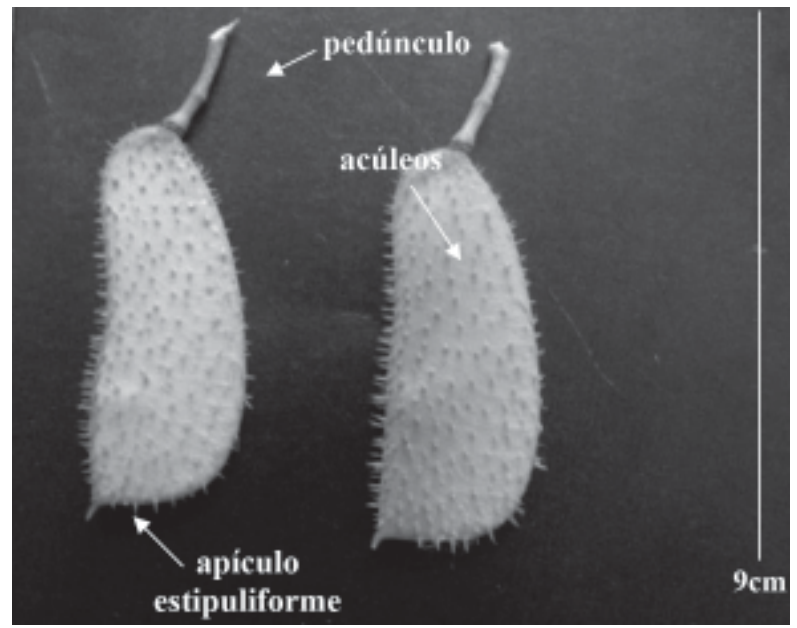

Figura 1 - Aspectos da morfologia externa do fruto de paubrasil (Caesalpinia echinata Lamarck).

Figure 1 - External morphological aspects of fruits of brazil wood (Caesalpinia echinata Lamarck). o hilo é circular, basal, heterócromo, de coloração roxa, e a micrópila é circular, basal e homócroma; apresenta funículo diminuto e amarelado; o embrião é axial, reto e invaginado, com cotilédones amarelados, planos, com ápice arredondado e forma variando de acordo com a semente; a base é sagitada e com uma fenda emarginada; e o eixo hipocótilo-radícula é reto, cilíndrico, amarelado, bem delimitado, invaginado, ultrapassando os cotilédones, com a plúmula apresentando-se bem visível.

\subsection{Caracterização morfológica da plântula} (Figura 4) - Com o intumescimento da semente,

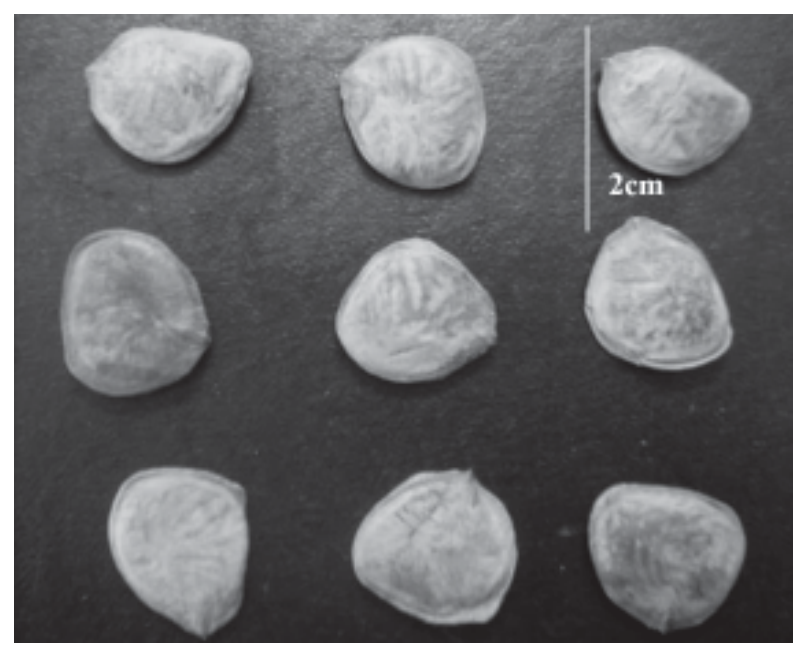

Figura 2 - Aspectos da morfologia externa das sementes de pau-brasil (Caesalpinia echinata Lamarck).

Figure 2 - External morphological aspects of seeds of brazil wood (Caesalpinia echinata Lamarck).

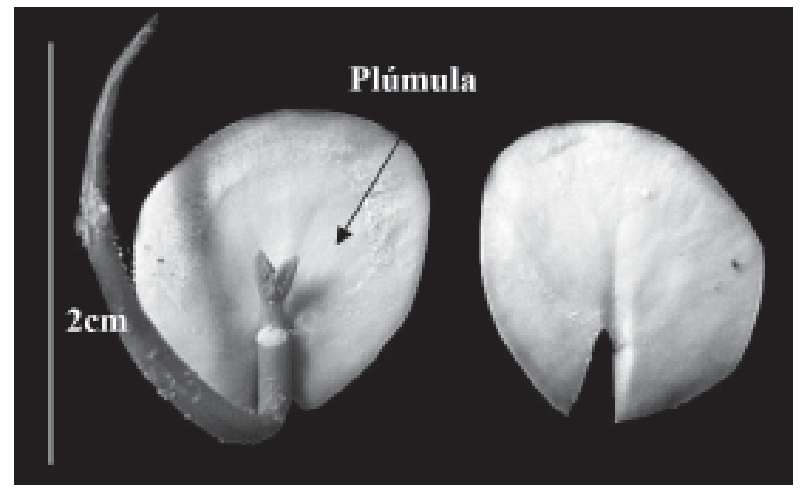

Figura 3 -Aspectos da morfologia interna das sementes de pau-brasil (Caesalpinia echinata Lamarck).

Figure 3 - Internal morphological aspects of seeds of brazil wood (Caesalpinia echinata Lamarck).

Revista Árvore, Viçosa-MG, v.39, n.3, p.505-512, 2015 
no início da germinação, o tegumento é rompido próximo à base, onde, no segundo e terceiro dias, se observa a protrusão da radícula, sendo esta de coloração branca, fina e cônica. A partir do quinto dia, a radícula vaise alongando e o tegumento se rompendo, mas ainda preso aos cotilédones. Gradativamente, há alongamento do hipocótilo, de coloração verde-clara, brilhoso e com o tegumento ainda preso, diferenciando-se do coleto que apresenta coloração marrom. Os cotilédones se abrem, mas não totalmente, surgindo, então, os protófilos. Há o aparecimento do epicótilo e, posteriormente, com o seu alongamento; apresenta coloração verde-clara e formato cilíndrico. A germinação é do tipo epígea fanerocotiledonar.

A plântula bem formada apresenta raiz primária do tipo axial, relativamente espessa, cilíndrica e de coloração branca; apresenta comprimento variando de 43,43 a 106,19 mm e diâmetro variando de 0,97 a $1,85 \mathrm{~mm}$; e as raízes secundárias apresentam comprimento variando de 3,24 a 7,25 mm e diâmetro variando de 0,42 a $0,74 \mathrm{~mm}$. O hipocótilo é verdeclaro, amarelado, glabro, cilíndrico, com comprimento variando de 45,04 a $52,90 \mathrm{~mm}$ e diâmetro variando de 1,25 a 1,51 mm. O epicótilo é piloso, cilíndrico, de coloração verde-clara, com comprimento variando de 33,25 a 36,16 mm e diâmetro variando de 1,03 mm a 1,1 mm. Os cotilédones são discolores (face adaxial

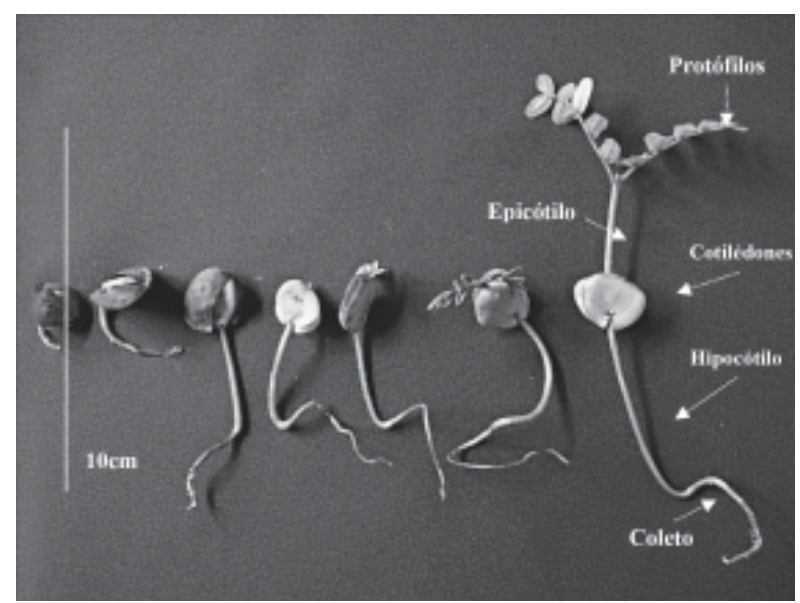

Figura 4 - Aspectos morfológicos da germinação até a fase de formação da plântula de pau-brasil (Caesalpinia echinata Lamarck).

Figure 4-Morphological aspects from germination to the development of plantules of brazil wood (Caesalpinia echinata Lamarck). apresenta coloração verde-escura e face abaxial verdeclara), sendo o ápice arredondado, base sagitada, com fenda até a metade e bordo inteiro; o comprimento varia de 14,11 a $14,53 \mathrm{~mm}$ e o diâmetro, de 12,83 a $16,96 \mathrm{~mm}$. As folhas são de coloração verde-escura, brilhosa, com comprimento variando de 8,14 a $9,75 \mathrm{~mm}$ e a largura, de 3,34 a 5,20 mm. Os folíolos são opostos dísticos, compostos, pilosos, com base arredondada e ápice acuminado, nervação peninérvea, bordo inteiro, com cinco pares de folíolos, paripenados. A ráqui é pilosa e apresenta diâmetro variando de $0,51 \mathrm{~mm}$ a $0,73 \mathrm{~mm}$.

\subsection{Caracterização morfológica da muda} (Figura 5) - A raiz primária é axial pivotante, de coloração marrom-escura, com comprimento variando de 12,00 a 16,80 cm e diâmetro de 1,38 a 2,27 mm; as raízes secundárias apresentam comprimento variando de 11,98

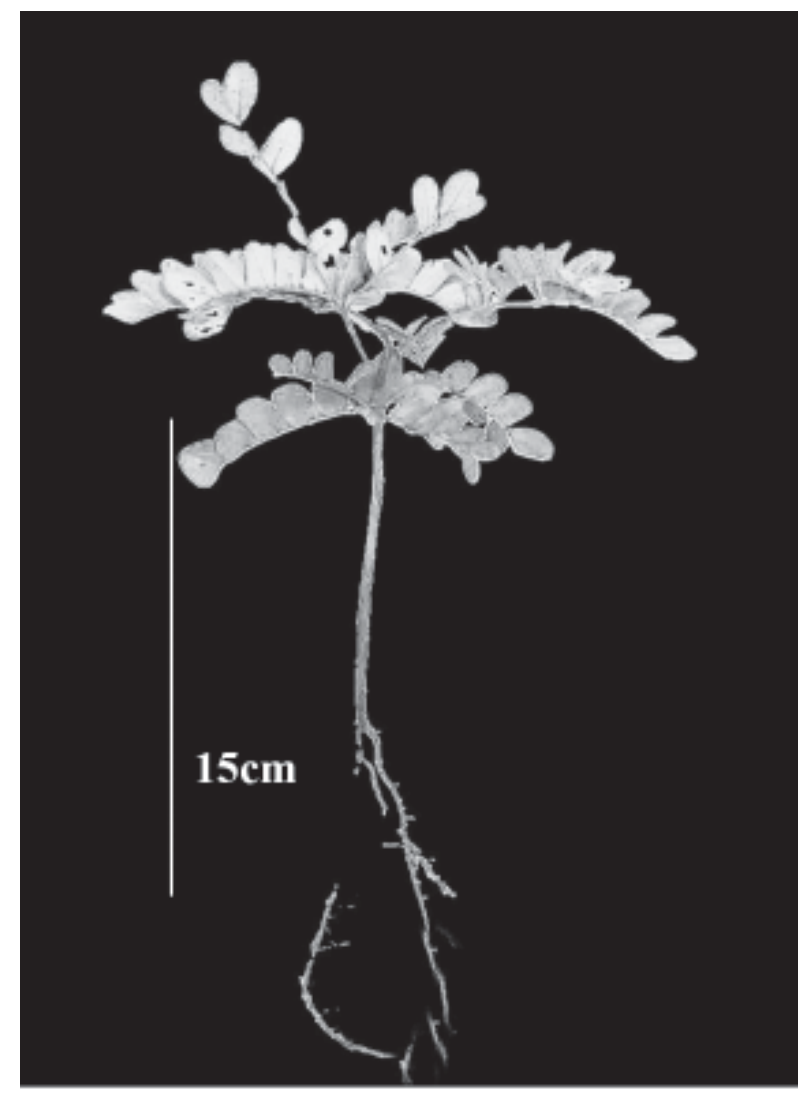

Figura 5 - Aspectos morfológicos da muda de pau-brasil (Caesalpinia echinata Lamarck).

Figure 5 -A. Morphological aspects of young seedlings of brazil wood (Caesalpinia echinata Lamarck).

Revista Árvore, Viçosa-MG, v.39, n.3, p.505-512, 2015 
a 34,29 mm e diâmetro variando 0,37 a 0,54 mm; e terciárias, com comprimento variando de 2,10 a 2,8 cm e diâmetro variando de 0,35 a $0,53 \mathrm{~mm}$, ramificadas finas e de coloração marrom-escura. O caule jovem é de coloração marrom, consistência lenhosa, cilíndrico, levemente curvado ou não, estriado verticalmente, com altura variando de 7,70 a 13,00 cm e diâmetro do colo variando de 2,40 a 2,90 mm; é rugoso, com lenticelas amareladas e circulares. $\mathrm{O}$ coleto apresenta comprimento e diâmetro variando de 1,30 a $3,50 \mathrm{~cm}$ e de 3,02 a $3,58 \mathrm{~cm}$, respectivamente. As folhas são compostas, recompostas, membranáceas, com comprimento variando de 8,8 a $12,3 \mathrm{~cm}$, paripenadas, alternas espiraladas, com cinco a seis pares de folíolos de comprimento variando de 12,32 a 14,91 mm e largura variando de 8,16 a 14,06 $\mathrm{mm}$, opostos dísticos e discolores (sendo verde-escuro na face adaxial e verde-claro na face abaxial); o ápice é arredondado a apiculado, base assimétrica, bordo inteiro, nervação peninérvea; são oblongos, brilhosos, glabros e sésseis; a nervura principal é proeminente na face abaxial e há presença de acúleos na base do pecíolo; a ráquis apresenta-se pilosa.

\section{DISCUSSÃO}

Segundo Teixeira et al. (2004), as características morfológicas de frutos e sementes de Caesalpinia echinata possuem consideráveis diferenças. Segundo esses autores, os frutos de Caesalpinia echinata são espinhosos e as sementes, redondas e assimétricas, com rafes e antirrafes com diferentes tamanhos. No entanto, constatou-se neste trabalho que os frutos apresentam acúleos e não espinhos verdadeiros, como mencionado por esses autores.

De acordo com Barroso et al. (1999), o fruto característico de Leguminosae Caesalpinioideae é o legume, podendo-se identificar 11 tipos diferentes. $\mathrm{Na}$ espécie estudada neste trabalho, o fruto é um legume, simples, mono ou polispérmico, coberto por acúleos, estipitado, seco e deiscente (quando ocorre leve torção das valvas).

Frutos do tipo legume deiscente, semelhante ao observado em Caesalpinia echinata Lam., são encontrados também em Caesalpinia pyramidalis (Tul.) (SILVA; MATOS, 1998) e Senna multijuga (Rich.) H.S. Irwin \& Barneby var. lindleiana (Gardner) H.S. Irwin \& Barneby (AMORIM et al., 2008). Deve-se considerar que Caesalpinia pyramidalis tem nova denominação taxonômica, Poincianella pyramidalis (Tul.) L.P. Queiroz.
Apesar de frutos polispérmicos serem os mais frequentemente observados na Subfamília Caesalpinioideae, algumas espécies como Schizolobium parahyba (Vell.) Blake, descrita por Pietrobom e Oliveira (2004) e Guibourtia hymenifolia (Moric.) J. Leonard, descrita por Battilani et al. (2011), apresentam apenas uma semente, ou seja, são monospérmicos.

De acordo com Barroso et al. (1999), as Leguminosae não apresentam sementes com tegumento interno, pois este é naturalmente reabsorvido. Nas sementes de Caesalpinia echinata Lam., também o tegumento interno é ausente, corroborando, assim, essa afirmativa. Em se tratando de cicatrizes visíveis, em muitas famílias o hilo pode apresentar características decisivas para a identificação de gêneros (BARROSO et al., 1999). Em Caesalpinia echinata Lam., a região hilar se apresenta com formato circular, basal e heterócromo, com coloração roxa.

Com relação às estruturas morfológicas internas, as sementes de Caesalpinia echinata Lam. apresentam embriões invaginados, com lobos marcados, conforme a descrição de Barroso et al. (1999). Embriões invaginados correspondem a um caráter encontrado, principalmente, nas Leguminosae Mimosoideae e Caesalpinioideae, em que os cotilédones comumente planos, crassos, carnosos ou retos, apresentam na base um sinus perfeito, com lobos bem marcados, entre os quais se articula o eixo hipocótilo-radícula, reto, curto ou longo.

A presença de endosperma é comum em Leguminosae Caesalpinioideae, mas em Caesalpinia echinata é completamente consumido durante o seu desenvolvimento embrionário. A presença de endosperma pode ser verificada em $32 \%$ dos gêneros de Caesalpinioideae estudados em cinco tribos, 110 gêneros e 1.900 espécies (GUNN, 1981). De acordo com esse autor, as sementes das espécies mais basais contêm mais endosperma do que as sementes das espécies mais derivadas. Tal caráter, quando presente, pode ser observado na forma de uma densa ou fina camada circundando o embrião, como pode ser observado em várias espécies dessa subfamília.

Em relação ao desenvolvimento de plântulas, de acordo com Pholhill et al. (1981), as espécies de Leguminosae Caesalpinioideae apresentam germinação predominantemente do tipo epígea. Outro fator de relevante importância para a caracterização das espécies, na fase inicial de desenvolvimento, refere-se ao fato de que, além do tipo de germinação epígea, os cotilédones 
podem permanecer encerrados nestes ou serem libertos, caracterizando, assim, a germinação epígeafanerocotiledonar, como observado em Guibourtia hymenifolia (Moric.) J. Leonard (BATTILANI et al., 2011), cuja característica também pode ser confirmada em Caesalpinia echinata Lam.

Em se tratando da identificação de aspectos da regeneração natural nos ecossistemas (chuva de sementes, banco de sementes e de plântulas), ou em projetos de recuperação de áreas degradadas por meio desta, ou por meio de semeadura direta, uma das primeiras preocupações é como identificar, com precisão, as espécies regenerantes. Na maioria das vezes, não se consegue identificar as espécies nessas fases ou, ainda, em algumas espécies nas fases jovens, por apresentarem heterofilia.

Assim, a caracterização morfológica também pode contribuir, de forma significativa, para identificar algumas espécies que são empregadas com a finalidade de recuperação de ecossistemas degradados.

\section{CONCLUSÃO}

A partir das análises descritivas da espécie estudada, as informações de frutos, sementes, plântulas e mudas podem ser empregadas com segurança em trabalhos de identificação das espécies, tanto em trabalhos de laboratórios e viveiros quanto em estudos de campo, quando se deseja avaliar a regeneração natural. Especial atenção pode ser dada ao tipo de fruto (seco, monospérmico ou polispérmico), e caracteres do embrião (axial, reto e invaginado), tipo de germinação epígea fanerocotiledonar e presença de acúleos nas fases jovens (plântulas e mudas) de Caesalpinia echinata Lam. são caracteres importantes para sua identificação. Os caracteres que são comuns a outras espécies de Fabaceae, da Subfamília Caesalpinioideae, corroboram o caráter taxonômico dos aspectos morfológicos.

\section{AGRADECIMENTOS}

Ao Programa de Iniciação Científica da Universidade Federal de Sergipe e à Coordenação de Pesquisa (CNPq/ UFS/COPES), pelo apoio.

\section{REFERÊNCIAS}

ABUD, H.F.; GONÇALVES, N.R.; REIS, R.G.E.; PEREIRA, D.S.; BEZERRA, A.M.E. Germinação e expressão morfológica de frutos, sementes e plântulas de Pilosocereus pachycladus Ritter. Revista Ciência Agronômica, v.41, n.3, p.468-474, 2010.
ALMEIDA JÚNIOR, E.B.; LIMA, L.F.; LIMA, P.B.; ZICKEL, C.S. Descrição morfológica de frutos e sementes de Manilkara salzmannii (Sapotaceae). Floresta, v.40, n.3, p.535-540, 2010.

AMORIM, I.L., DAVIDE, A.C., FERREIRA, R.A.; CHAVES, M.M. Morfologia de frutos, sementes, plântulas e mudas de Senna multijuga (Rich.) H.S. Irwin \& Barneby var. lindleiana (Gardner) H.S. Irwin \& Barneby - Leguminosae Caesalpinioideae. Revista Brasileira de Botânica, v.31, n.3, p.507-516, 2008.

BARRETTO, S.S.B.; FERREIRA, R.A. Aspectos morfológicos de frutos, sementes, plântulas e mudas de Leguminosae Mimosoideae:

Anadenanthera colubrina (Vellozo) Brenan e Enterolobium contortisiliquum (Vellozo) Morong. Revista Brasileira de Sementes, v.33, n.2, p.223-232, 2011.

BARROSO, G.M.; MORIM, M.P.; PEIXOTO, A.L.; ICHASO, C.L.F. Frutos e sementes: morfologia aplicada à sistemática de dicotiledôneas. Viçosa: UFV, 1999. 443p.

BATTILANI, J.L.; SANTIAGO, E.F.; DIAS, E.S. Morfologia de frutos, sementes, plântulas e plantas jovens de Guibourtia hymenifolia (Moric.) J. Leonard (Fabaceae). Revista Árvore, v.35, n.5, p.1089-1098, 2011.

BATISTA, G.S.; COSTA, R.S.; GIMENES, R.; PIVETTA, K.F.L.; MÔRO, F.V. Aspectos morfológicos dos diásporos e das plântulas de Syagrus oleracea (Mart.) Becc - Arecaceae. Comunicata Scientiae, v.2, n.3, p.170-176, 2011.

FERREIRA, R.A.; BOTELHO, S.A.; DAVIDE, A.C.; MALAVASI, M.M. Morfologia de frutos, sementes, plântulas e mudas de Dimorphandra mollis Benth - faveira (Leguminosae Caesalpinioideae). Revista Brasileira de Botânica, v.24, n.3, p.303-309, 2001.

GONÇALVES, E.G.; LORENZI, H. Morfologia vegetal: organografia e dicionário ilustrado de morfologia de plântulas vasculares. 2.ed. São Paulo: Instituto Plantarum de Estudos da Flora, 2011.

GUNN, C.R. Seed topography in the Fabaceae. Seed Science and Tecnology, v.9, p.737-757, 1981.

Revista Árvore, Viçosa-MG, v.39, n.3, p.505-512, 2015 
GURSKI, C.; DIAS, ES.; MATTOS, E.A. Caracteres das sementes, plântulas e plantas jovens de Ormosia arborea (vell.) harms e Ormosia fastigiata tul. (Leg- Papilionoideae). Revista Árvore, v.36, n.1, p.37-48, 2012.

MOURÃO, K.S.M.; DIAS-PINTO, D.; SOUZA, L.A.; MOSCHETA, I.S. Morfoanatomia de plântula e do tirodendro de Trichilia catigua A. Juss., T. elegans A. Juss. e T. pallida Sw.(Meliaceae). Acta Scientiarum. Biological Sciences, v.24, n.2, p.601-610, 2002.

OLIVEIRA, L.Z.; CESARINO, F.; PANTOJA, T.F.; MÔRO, F.V. Aspectos morfológicos de frutos, sementes, germinação e plântulas de Hymenolobium petraeum. Ciência Rural, v.40, n.8, p.1732-1740, 2010.

PIETROBOM, R.C.V.; OLIVEIRA, D.M.T. Morfoanatomia e ontogênese do pericarpo de Schizolobium parahyba (Vell.) Blake (Fabaceae, Caesalpinioideae). Revista Brasileira de Botânica, v.27, n.4, p.767-779, 2004.

POLHILL, R.M.; RAVEN, P.H.; STIRTON, C.H. Ecolution and systematics of the Leguminosae. In: POLHILL, R.M.; RAVEN, P.H. (Eds.). Advances in legume systematics. Part 1. Kew: Crown Copyright, 1981. p.1-25.

RAMOS, L.M.; COSTA, R.S.; MÔRO, F.V.; SILVA, R.C. Morfologia de frutos e sementes e morfofunção de plântulas de Moringa (Moringa oleifera Lam.) Comunicata Scientiae, v.1, n.2, p.156-160, 2010.

REGO, S.S..; NOGUEIRA, A.C.; KUNIYOSHI, Y.S.; SANTOS, A.F. Caracterização morfológica do fruto, da semente e do desenvolvimento da plântula de Blepharocalyx salicifolius (H.B.K.) Berg. e Myrceugenia gertii Landrum - Myrtaceae. Revista Brasileira de Sementes, v.32, n.3, p.52-60, 2010.
RODERJAN, C.V. Morfologia do estádio juvenil de 24 espécies arbóreas de uma floresta com araucária. 1983. $148 \mathrm{f}$. Dissertação (Mestrado em Ciências Florestais) Universidade Federal do Paraná, Curitiba:

SILVA, B.M.S.; CARVALHO, N.M. Efeitos do estresse hídrico sobre o desempenho germinativo da semente de faveira (Clitoria fairchildiana R.A. Howard. - Fabaceae) de diferentes tamanhos. Revista Brasileira de Sementes, v.30, n.1, p.55-65, 2008.

SILVA, K.B.; ALVES, E.U.; BRUNO, R.L.A.; MATOS, V.P. Caracterização morfológica de frutos, sementes e germinação de Sideroxylon obtusifolium (Roem. e Schult.) Penn. (Sapotaceae). Revista Árvore, v.36, n.1, p.59-64, 2012.

SILVA, L.M.M.; MATOS, V.P. Morfologia de frutos, sementes e plântulas de catingueira (Caesalpinia pyramidalis Tul. - Caesalpinaceae) e de juazeiro (Zizyphus joazeiro Mart. Rhamnaceae). Revista Brasileira de Sementes, v.20, n.2, p.25-31, 1998.

SOUSA, D.M.M.; BURNO, R.L.A.; DORNELA, C.S.M.; ALVES, E.U.; ANDRADE, A.P.;

NASCIMENTO, L.C. Caracterização morfológica de frutos e sementes e desenvolvimento pósseminal de Tamarindus indica L. - Leguminosae: Caesalpinioideae. Revista Árvore, v.34, n.6, p.1009-1015, 2010.

TEIXEIRA, S.P.; CARMELLO-GUERREIRO, S.M.; MACHADO, S.R. Fruit and seed ontogeny related to the seed behaviour of two tropical species of Caesalpinia (Leguminosae). Botanical Journal of the Linnean Society, v.146, p.57-70, 2004.

ULIBARRI, E.A. Sinopsis de Caesalpinia y Hoffmanseggia (Leguminosae-Caesalpinioideae) de Sudamérica. Darwiniana, v.34, p.299-348, 1996. 